\title{
A CONSTRUÇÃo CULTURAL DA SEXUALIDADE INFLUENCIADA PELA MUTAÇÃO SOCIAL E O RECONHECIMENTO DA ENTIDADE FAMILIAR
}

\author{
Rachel Lopes Queiroz ${ }^{1}$, Danilo Rodrigues Ferreira ${ }^{2}$ \\ ${ }^{1}$ Docente do Curso de Direito da UNOESTE. ${ }^{2}$ Discente do Curso de Direito da UNOESTE.
}

\section{RESUMO}

O presente trabalho propõe a discussão acerca da construção cultural da sexualidade frente aos fenômenos sociais que ocorrem conforme o dinamismo contido no convívio da agremiação geral e a análise do afeto como valor jurídico para galgar alicerce juntamente com os princípios da Constituição Federal de 1988, estes utilizados como panacéia para a eliminação da celeuma contida no ordenamento pátrio. A sociedade contemporânea, ainda impõe um padrão heterossexual, apontando tão logo o caráter desviante da homossexualidade. No entanto, prospera a necessidade de regulamentação da união homoafetiva. Interessante ressaltar, a valorização do afeto, que revela que a sexualidade é uma escolha pessoal de como viver, repelindo o padrão ao qual se impõe a sociedade. Há um novo espaço de realização familiar, com fundamento no afeto, que tem valor jurídico imensurável para a satisfação das necessidades básicas do ser humano. Os princípios constitucionais da Igualdade e Dignidade da Pessoa Humana garantem a desmistificação contida nas uniões homoafetivas, dando respaldo a identidade pessoal de cada indivíduo, ao livre desenvolvimento de sua personalidade, bem como também ao seu direito de autodeterminação sobre os assuntos que concernem a sua intimidade. Eles propiciam o respeito mútuo independente de sua escolha sexual ou forma de união afetiva. A repercussão no poder midiático aduz aos benefícios da aceitação das relações homoafetivas, como forma de regulamentação dos seus Direitos civis e a nova edificação dos pilares da sociedade.

Palavras-chave: União Homoafetiva, Sexualidade, Direitos civis.

\section{THE CULTURAL CONSTRUCTION OF THE SEXUALITY INFLUENCED FOR THE SOCIAL MUTATION AND THE RECOGNITION OF THE FAMILIAR ENTITY}

\begin{abstract}
This paper proposes a discussion about the cultural construction of sexuality in the face of social phenomena that occur as the momentum contained in the general conviviality of the party and the analysis of affect as a legal value to climb along with the bedrock principles of the Constitution of 1988, they used as panacea for the elimination of land contained in the patriotic uproar. Contemporary society imposes a heterosexual pattern, pointing as soon as the deviant nature of homosexuality. The homo marriage leads to social disapproval for non-recognition, which should not prosper, but must occur to change the concept of the family. Interesting note, the appreciation of affection, providing support in reasoning, showing that sexuality is a personal choice of how to live and should not follow the standard to which they impose on society as well as for having a new space for holding family reasons this affection, having legal value in meeting the basic needs of human beings. The Constitutional principles of Equality and Human Dignity guarantee contained in the demystification homoafetivas unions, ensuring the personal identity of each individual for the free development of his personality, but also the right to self-determination on matters that concern their particular sphere, well as the respect of his peers, regardless of their sexual choice or form of affective union. The impact on media power adds to the benefits of acceptance homoafetivas relations as a way of regulating their civil rights and new building of the pillars of society.
\end{abstract}

Keywords: Union homo, Sexuality, Civil Rights. 


\section{INTRODUÇÃO.}

O presente trabalho propõe debater uma nova concepção em relação à sexualidade, demonstrando que esta é um construto social fundado sobre os corpos, que não se limita ao biológico.

Destarte, a cultura desempenha o papel de produzir e tornar reprodutíveis padrões que se moldam em seu seio, feito isso por meio de relações de poder, legitimando-se determinadas condutas e subordinando-se outras, onde a homossexualidade se enquadra entre uma das condutas subordinadas, sendo rotulada como desviante. Serve ela, ainda, à afirmação da matriz heterossexual como algo natural e imutável.

O Direito vinculado a uma ideologia dominante reproduz por meio da matriz heterossexual, o padrão da normalidade, e exclui a sexualidade homossexual. Asseverando que, por essa forma, não é considerado como natural, os homossexuais constituírem uma entidade familiar.

À partir do desenvolvimento de uma perspectiva civil-constitucional, a luz do valor da Dignidade da Pessoa Humana, cresce a possibilidade de se conceber as uniões homossexuais enquanto entidades familiares, tendo como característica de suma importância, o afeto.

Tal perspectiva representa um meio para a desvariação do paradigma do senso comum teórico dos juristas, o qual atua, no âmbito do Direito, como empecilho à regulamentação legal e a efetivação dos Direitos dos homossexuais.

O resultado desse artigo deriva da produção parcial do desenvolvimento de um Projeto de Pesquisa Docente e Discente.

1. Homossexualidade e o Desenvolvimento da Sexualidade frente à Construção Social
O estudo ora apresentado aborda a sexualidade como algo fundamentado no afeto e na construção social, como elementos que justificam o reconhecimento da união de pessoas do mesmo sexo.

Rios (2002, p. 120) afirma que conceber a homossexualidade como construção social significa postular que a identificação de alguém ou qualificação de seus atos, sob uma outra orientação sexual, só tem sentido, na medida em que, em um certo contexto histórico cultural, houver a institucionalização de papéis e de práticas próprias para cada um dos sexos, em que atração pelo sexo oposto ou pelo mesmo sexo seja considerada um elemento relevante, capaz inclusive de impor diferenças de tratamento entre os indivíduos. Nesta perspectiva, relativizase a condição homo ou heterossexual como critério de distinção, tanto que em outras culturas tal característica pode ser irrelevante ou assumir conotações diversas.

A evolução da sociedade retrata a forma como o ser humano vive e desenvolve a sua sexualidade, demonstra a formação da identificação sexual de uma pessoa, a diferenciação de escolha ou mesmo de posição homossexual ou heterossexual e rotula o ser humano, de forma preconceituosa, não sendo aceita no convívio do corpo social. Todavia há que se ressaltar a edificação da sexualidade, afirmada assim por Louro (1997, p. 25):

A sexualidade é uma
constituinte do sujeito. As
identidades sexuais
constituem-se através da forma
com que a sexualidade é
vivida: com parceiros do sexo
oposto, com parceiros do
mesmo sexo, com parceiros de
ambos os sexos ou sem
parceiros.

Acerca da alusão asseverada Giddens (1993, p. 25) afirma que hoje em dia a sexualidade tem sido descoberta, revelada e 
propícia, conforme o desenvolvimento de estilos de vida bastante variados. É algo que cada um cultiva no transcorrer de sua vida, não mais considerando somente como uma condição natural e física do indivíduo ou um estado de coisas preestabelecido. De algum modo, o tema tem de ser investigado, uma vez que a sexualidade funciona como um aspecto maleável do eu, um ponto de conexão primário entre o corpo, a autoidentidade e as normas sociais.

Desse modo, a sexualidade torna-se livre, ao mesmo tempo que gay é algo que pode "ser" e "descobrir-se ser"; a sexualidade abre-se a muitos propósitos (GIDDENS, 1993, p. 24).

Atesta Foucault (1999, p. 100) que a sexualidade deve ser espreitada em conformidade a um dispositivo histórico, negando uma posição de gênero da natureza:

\begin{abstract}
Não se deve concebê-la como uma espécie de dado da natureza que o poder é tentado a pôr em xeque, ou como um domínio obscuro que o saber tentaria, pouco a pouco, desvelar. A sexualidade é o nome que se pode dar a um dispositivo histórico: não à realidade subterrânea que se apreende com dificuldade, mas à grande rede da superfície em que a estimulação dos corpos, a intensificação dos prazeres, a incitação ao discurso, à formação dos conhecimentos, o reforço dos controles e das resistências, encadeiam-se uns aos outros, segundo algumas grandes estratégias de saber e de poder.
\end{abstract}

Concernente a construção social da sexualidade, de uma moldura atinente à historicidade, tomamos a lição dada por Weeks (2001, p. 43) aduzindo que só podemos compreender as atitudes em relação ao corpo e a sexualidade em seu contexto histórico específico, explorando as condições historicamente variáveis que dão origem a importância atribuída à sexualidade num momento particular e apreendendo as várias relações de poder que modelam o que vem a ser visto como comportamento normal ou anormal, aceitável ou inaceitável.

Desta feita consolidamos que, a sexualidade examinada a partir de uma visão histórica, construída socialmente, não pode ser observada como uma forma de aceitação do sujeito, sob as condições valorativas daquilo que pode ser certo ou errado, tampouco como uma mera imposição social. Mas, de uma forma flexível, alusiva a uma identidade sexual conquistada a partir dos acontecimentos da agremiação geral. Da mesma forma, o Homem não deve se sentir em uma posição de reprovação, devendo-se consagrar a sexualidade, como algo que se altera e transforma, sem gerar transtornos ou discriminações.

Comungando a asserção ora aludida, Louro (1997, p. 12) pondera:

As identidades sociais,
constituídas não só pelas
identidades sexuais, mas pelas
identidades de gênero, raça,
nacionalidade, classe etc., são
definidas nos âmbitos histórico
e cultural. Portanto, assim
como as identidades sociais, as
sexuais possuem um caráter
fragmentado, instável, histórico
e plural. Ultimando a contenda, fixamos em empregar ser a sexualidade, elemento da personalidade do ser humano, em que 0 crescimento completo está sujeito à satisfação basilar das necessidades humanas, como desejo de contato, prazer, carinho, intimidade e amor. Sem olvidar, asseveramos que a edificação da sexualidade é o ponto central para o desenvolvimento individual, interpessoal e social do ser humano. 
2 Heterossexualidade: Padrão social - fator preponderante à imposição de invisibilidade da concepção homossexual

A forma com que a cultura cria a observação da sexualidade sendo correta a heterossexual transforma a homossexual submissa àquela, que se torna padrão para a sociedade, criando a idéia de que esta é desviante. Pressupõe uma medida a ser caminhada e entendida socialmente como correta, causando consequentemente, posições discriminatórias que se tornam normais sob a análise das pessoas que se dizem normais, por conta do padrão por elas criado e vivído, o que torna invisível a sexualidade homossexual.

Acerca da menção, Rios (2002, p. 122) afirma:

De fato, a designação da condição homossexual como desviante pressupõe a definição de padrões de conduta e de identificação a partir da premissa da "normalidade heterossexual", o que requer, por sua vez, a assunção do binômio heterossexual/homossexual como par conceitual fundamental para a constituição das identidades individuais.

A maneira imutável dessa visão revela o modelo de identidade sexual do sujeito. Segundo Fachin (2003, p. 122), o sistema jurídico, cioso de seus mecanismos de controle, estabelece, desde logo, com o nascimento, uma identidade sexual, teoricamente imutável e una. Essa rigidez não leva em conta dimensões outras, também relevantes, no plano das questões sociais e psicológicas. Desse modo, o papel de gênero se apresenta como uma expressão pública dessa identidade.

No que tange ao binômio heterossexual/homossexual, assevera Rios (2002, p. 123) que a divisão dos sujeitos nestas categorias (homossexual/heterossexual), por si só, reproduz as dominações por elas instituídas e mantidas, ao invés de promover sua superação, que segundo o próprio autor, já começa a acontecer.

Na mesma linha de análise Hawkes (1996, p. 135-140), aponta que o advento de um estilo de vida, característico do final do século $X X$, as identidades individuais - inclusive no plano sexual - derivam das possibilidades de escolha propiciadas pelo desenvolvimento complexo da sociedade de consumo.

A modernidade tardia, sugere Giddens, libertou a sexualidade dos cofins, de uma única hegemonia e recolocou-a num 'pluralismo sexual'. A mudança significativa que fez romper estas características não foi conseqüência direta da 'era permissiva', mas de um movimento no qual a sexualidade enquanto 'fixidez' foi suplantada pela identidade sexual definida e estruturada pela escolha individual, onde a escolha sexual tornou-se mais um elemento na escolha do estilo de vida. Historicamente, esta mudança ocorreu num espaço de tempo tão curto quanto suas conseqüências potencialmente revolucionárias. Os modos de pensar sobre o sexo que nos deram a ciência do sexo, com as rígidas distinções entre o normal e o anormal, produziram como conseqüência direta uma série de dados empíricos sobre os comportamentos sexuais adotados pelas pessoas - que diferem dos trabalhos dos primeiros sexologistas em dois sentidos. Primeiro, eles conscientemente fogem de prejulgamentos na forma de classificação. Segundo, eles não somente tornam possível, como voltaram-se diretamente, ao consumo por leigos (cada vez mais desde Kinsey, cujos volumes eram publicados a preços proibitivamente altos e sujeitos a vendas limitadas). Esses estudos confrontam explicitamente posições antes intocadas. Entrevistados que 
voluntariamente confessaram seus encontros sexuais casuais, descompromissados e não monogâmicos, comparáveis a uma fluidez nas escolhas sexuais. Eles também revelaram a aridez erótica e emocional daqueles relacionamentos sexuais que, ao menos superficialmente, aderiram as normas. [...] É também por meio deste processo de reflexão que as distinções entre a 'nossa normalidade' e 'a perversão deles' são maculadas senão dissolvidas. 'Diversidade sexual, embora ainda considerada por muitos grupos hostis como a perversão, deixou de ser uma referência freudiana tomada a partir de casos exemplares para tornar realidade cotidiana no mundo social (HAWKES, 1996 apud GIDDENS, 1993, p. 22-25).

Desta feita, no que tange os setores do movimento homossexual, claro é de se entender suas reservas, referente à defesa aos direitos da homossexualidade, pois o que impera é a força das estruturas de dominação e a visível desigualdade que enfrentam os homossexuais.

Todavia, Giddens (1993, p. 45) afirma que a modernidade está associada à socialização do mundo natural - a substituição progressiva das estruturas e dos acontecimentos que eram parâmetros externos da atividade humana por processos socialmente organizados. Não apenas a própria vida social, mas também o que costumava ser "natureza" passa a ser dominado por sistemas socialmente organizados.

A reprodução um dia foi parte da natureza e a atividade heterossexual era inevitavelmente o seu ponto principal. Uma vez que a sexualidade tornou-se um componente "integral" das relações sociais, como resultado de mudanças já discutidas, a heterossexualidade não é mais um padrão pelo qual tudo o mais é julgado. Ainda não atingimos um estágio em que a heterossexualidade é aceita como apenas uma preferência entre outras, mas esta é a implicação da socialização da reprodução.

\subsection{Dominação de poder}

As relações de poder exercem domínio frente o sexo trazendo uma repressão quanto o que se encontra na lei, enquanto constitutiva do desejo, travando discussões acerca das relações atinentes ao poder e o sexo.

Consoante a relação negativa e repressiva do poder e do sexo, Foucault (1999, p. 81) aduz:

Com respeito ao sexo, o poder jamais estabelece relação que não seja de modo negativo: rejeição, exclusão, recusa, barragem ou, ainda, ocultação e mascaramento. O poder não "pode" nada contra o sexo e os prazeres, salvo dizer-lhes não; se produz alguma coisa, são ausências e falhas; elide elementos, introduz descontinuidades, separa o que está junto, marca fronteiras. Seus efeitos tomam a forma geral do limite e da lacuna.

No âmbito legal instancia de regra denominada como jurídico-discursivo, em que a limitação do poder é ditada pelo texto da lei.

Naquilo que concerne ao sexo, o legislador reduz a interpretação sob o prisma do regime binário: daquilo que é lícito ou ilícito, permitido e proibido.

Desta forma, o legislador detêm o poder de inteligibilidade sobre o modo de ação à respeito do sexo.

Por último aponta uma [...] unidade do dispositivo, onde o poder sobre 0 sexo se exerceria do mesmo modo a todos os níveis. De alto a baixo, em suas decisões globais como em suas intervenções capilares, não importando os aparelhos ou instituições em que se apóie, agiria de maneira uniforme e maciça; funcionaria de acordo com as engrenagens simples e infinitamente 
reproduzidas da lei, da interdição e da censura: do Estado à família, do príncipe ao pai, do tribunal a quinquilharia das punições quotidianas, das instâncias da dominação social às estruturas constitutivas do próprio sujeito, encontrar-se-ia, em escalas diferentes apenas, uma forma geral de poder. Essa forma é o direito, com o jogo entre o lícito e o ilícito, a transgressão e o castigo. Em face de um poder, que é lei, o sujeito que é constituído como sujeito - que é "sujeitado" - é aquele que obedece [...] do cidadão ante o Estado [...]. Poder legislador, de um lado, e sujeito obediente do outro ${ }^{1}$. (FOUCAULT, 1999, p. 82).

A lógica do poder sobre o sexo é a lógica paradoxal da lei.

É necessária a repressão à teoria da lei.

O contexto apresenta novos modelos de relações afetivas, com o respeito à identidade sexual e cultural do indivíduo e a formação de variadas formas de entidade familiar.

Desta feita, a construção cultural da sexualidade influenciada pela mutação social demanda uma postura diferenciada dos juristas, os quais devem auferir a definição do domínio específico do conteúdo legal à ser regulamentado e seus instrumentos, considerando a ideologia que permeia todas as relações de poder, para que ao final, não se tome o direito como modelo ou código, mas se analise a subsunção dos novos paradigmas ao sistema jurídico

\section{CONSIDERAÇÕES FINAIS}

A evolução da sociedade, juntamente como a forma em que se vive à sexualidade, demonstra o desenvolvimento de uma identificação sexual de uma pessoa, o padrão heterossexual imposto socialmente rotula o ser humano de forma preconceituosa, por considerar

\footnotetext{
${ }^{1}$ FOUCAULT, M. 1999, p. 82.
}

a união de pessoas do mesmo sexo em uma diferenciação de escolha, apontada como desviante, reforçando também a idéia com as diversas formas de dominação e poder, sedimentando a imposição da invisibilidade homossexual, que é ocultada, reprimida, inaceitável, tendo a homossexualidade um caráter reprovado, por não ser legitimada, servindo apenas como algo a ser exemplificado como inverso ao normal (heterossexual).

Todavia, a sexualidade é algo que cada sujeito possui, ou cultiva, não sendo algo condicionado de maneira natural que um indivíduo deva aceitar como estado preestabelecido, assim deve-se observar a sexualidade como aspecto maleável do eu, um ponto de conexão primário entre o corpo, a autoidentidade e as normas sociais.

A sexualidade deve ser vista como um construído, de acordo com as mutações sociais, observada em conformidade a um dispositivo histórico, de forma flexível referente a uma identidade sexual conquistada a partir dos acontecimentos da agremiação geral, destacando também a constituinte do ser humano, que não deve se sentir em uma posição de reprovação, devendo-se consagrar a sexualidade como algo que se altera, transforma e não de forma imutável.

O conceito de família, bem como a sexualidade, é mutável, observado assim consoante ao dinamismo social, às mudanças notórias decorrentes dos fenômenos sociais, tendo uma evolução constante, mesmo que paulatina, sendo que, neste meio encontra-se o direito que não deve se silenciar, tendo a obrigação de dar respostas as discussões encontradas, caso da celeuma contida nas uniões homoafetivas.

O valor do afeto trás fundamentação significativa a um novo espaço de realização familiar, sendo a sexualidade uma escolha 
pessoal de como viver, sem óbice da empregada na sociedade como padrão. A família é algo que todas as pessoas sem distinção, tomam como desejo de constituí-la, devendo considerar o afeto como um valor jurídico para a satisfação das necessidades humanas basilar. Há que se ressaltar que, não é mais o indivíduo que existe para a família e para o casamento, mas a família e 0 casamento existem para 0 seu desenvolvimento pessoal, em busca de sua aspiração à felicidade.

A união homoafetiva merece respaldo em seu reconhecimento enquanto entidade familiar, por possuir base nos princípios consagrados da em nossa Lei Maior, como o Princípio da Igualdade, Liberdade e Dignidade da Pessoa Humana; destacando esse último por ser considerado fundamento de todo o sistema dos Direitos Fundamentais.

No que tange aos avanços e conquistas para o reconhecimento da união homoafetiva como entidade familiar, pontuamos o Projeto de Lei 2.285/2007, que dispõe sobre o Estatuto das Famílias, que merece respaldo para aprovação por aduzir informações de suma importância para a sedimentação das reivindicações, apontando neste o reconhecimento a união de pessoas do mesmo sexo como entidade familiar. Este projeto de lei teve apoio na Conferência Nacional LGBT (Lésbicas, Gays, Bissexuais, Travestis e Transexuais), sendo esta a primeira com essa abordagem, no mundo. Naquele momento, debateram as questões mais diversas, avaliando e propondo estratégias de políticas públicas, as quais trouxeram pontuações de maneira significativa ao reconhecimento dessas uniões. Os resultados culminaram na elaboração do Plano Nacional de Promoção da Cidadania e Direitos Humanos LGBT,

Ressaltamos em afirmar que, mesmo não havendo aprovação de projetos de lei que dizem respeito a essas uniões, esses fundamentos expostos deram respaldo ao preterido reconhecimento como entidade familiar, sendo que, não havia um senso comum teórico dos juristas, pois alguns julgadores estavam agregados a costumes que se tornam verdades de princípios.

Todavia a relativização por parte de alguns acórdãos e julgadores, em coletânea jurisprudencial, determinou o avanço na busca do reconhecimento das uniões homoafetivas como entidades familiares. Interessante são as decisões, tanto na relativização como nas contrárias que expressam o senso comum teórico que deve ser eliminado para que possamos ver em um futuro próximo a efetiva aplicação dos direitos que todas as pessoas possuem, sem discriminação, fazendo valer o valor da dignidade da pessoa humana a essas pessoas que reivindicam a solidificação de tais direitos, para que assim possamos vivenciar uma nova moldura jurídica do Direito pátrio, realizando o sonho de uma sociedade justa, fraterna e igualitária.

As conclusões das idéias denotam a alteração do senso comum teórico dos juristas, visto como óbice na busca de decisões pacíficas.

De acordo com a maneira hodierna que se encontram os fenômenos sociais e a pontuação da relativização encontrada em grande parte dos julgados, em diversos Tribunais nos Estados de nossa Federação, verificamos a busca da eliminação de preconceitos e o reconhecimento da união homoafetiva, enquanto entidade familiar.

\section{REFERENCIAS}

BRAUNER, M. C. C. (org.). O Direito de Família: descobrindo novos caminhos. Porto Alegre: La Salle, 2001. p. 255.

BRAUNER, M. C. C. (org.). Direito Sexualidade e Reprodução humana: conquistas médicas e o debate bioético. Rio de Janeiro: Renovar, 2003. p. 223. 
BOURDIEU, P. A dominação masculina. 3.ed.

Rio de Janeiro: Bertrand Brasil, 2003.

FACHIN, L. E. Direito de família: elementos críticos à luz do novo código civil brasileiro. 2.ed. Rio de Janeiro: Renovar, 2003.

FOUCAULT, M. História da sexualidade I: a vontade de saber. 13.ed. Rio de Janeiro: Edições Graal, 1999. p. 81-83.

GIDDENS, A. A transformação da intimidade: sexualidade, amor e erotismo nas sociedades modernas. Tradução de Magda Lopes. São Paulo: Editora da Universidade Estadual Paulista, 1993. p. $135-140$.

HAWKES, G. A sociology of sex and sexuality. Philadelphia: Open University Press, 1996. p. 22, 25-45.

LOURO, G. L. Gênero, sexualidade e educação: uma perspectiva pósestruturalista. Petrópolis: Vozes, 1997.

PINTO, P. M. Notas sobre o direito ao livre desenvolvimento da personalidade e os direitos de personalidade no direito português. In: SARLET, I. W. (org.). A constituição concretizada: construindo pontes com o público e o privado. Porto Alegre: Livraria do Advogado, 2000. p. $61-83$.

RIOS, R. R. O princípio da igualdade e a discriminação por orientação sexual: a homossexualidade no direito brasileiro e norteamericano. São Paulo: Editora Revista dos Tribunais, 2002.

WEEKS, J. O corpo e a sexualidade. In: LOURO, G. L. (org.). O corpo educado: pedagogias da sexualidade. 2.ed. Belo Horizonte: Autêntica, 2001. 